\title{
Challenges and Opportunities in Contemporary Participatory Design
}

Robertson, Toni; Simonsen, Jesper

Published in:

Design Issues

DOI:

10.1162/DESI_a_00157

Publication date:

2012

Document Version

Early version, also known as pre-print

Citation for published version (APA):

Robertson, T., \& Simonsen, J. (2012). Challenges and Opportunities in Contemporary Participatory Design. Design Issues, 28(3), 3-9. https://doi.org/10.1162/DESI_a_00157

\section{General rights}

Copyright and moral rights for the publications made accessible in the public portal are retained by the authors and/or other copyright owners and it is a condition of accessing publications that users recognise and abide by the legal requirements associated with these rights.

- Users may download and print one copy of any publication from the public portal for the purpose of private study or research.

- You may not further distribute the material or use it for any profit-making activity or commercial gain.

- You may freely distribute the URL identifying the publication in the public portal.

Take down policy

If you believe that this document breaches copyright please contact rucforsk@kb.dk providing details, and we will remove access to the work immediately and investigate your claim. 


\section{Challenges and Opportunities in Contemporary Participatory Design}

Toni Robertson and Jesper Simonsen

The core of Participatory Design is the direct involvement of people in the co-design of tools, products, environments, businesses, and social institutions to ensure these work in ways that are more responsive to human needs. In particular, it has developed a diverse collection of principles and practices all aimed at directly involving people in the co-design of the technologies they use. This process has generated many of the design tools and techniques that have gone on to become best practice in the development of current information and communications technologies and product design. These include: various kinds of design workshops to collaboratively envision future products and practices; scenarios and related tools to include those who will use whatever is being designed; various forms of representations used during the process; and iterative prototyping to enable all participants in the design process to interrogate developing designs and to ground the design conversations ${ }^{1}$. Participatory Design has also pioneered and developed some of the basic research questions, methods and research agendas that have been taken up in the recent focus on design research ${ }^{2}$ within more traditional design environments, including the notion of innovation through participation.

Increasingly, participatory designers have extended their concerns to involving people in the design of the tools, environments, businesses, and social institutions in which these technologies are embedded. These widened contexts have been reflected in the themes of recent conferences in Participatory Design and in the substantive focus of the research presented in them.

\section{Participatory Design: a brief overview}

The origins of Participatory Design are broad and lie in the restless and exhilarating days of the 1970s when so many people demanded a say in decision-making about many aspects of their lives. This was a time when designers from a number of domains sought ways to work together with those whose lives would be affected by 
their designs. Community arts projects were common, architects and planners became involved in the participatory planning of communities housing, and a major conference on the theme of design participation was sponsored by the Design Research Society in Manchester ${ }^{3}$.

In Europe and Scandinavia, as part of the workplace democracy movement, information technology designers responded to the transformation of workplaces driven by the introduction of computers. Writing of this early work, Morten Kyng observed: As part of the transformation of the workplace working conditions for many end users have changed dramatically, and not always for the better ${ }^{4}$. Participatory Design researchers and Scandinavian trade unions initiated a range of activities, not just to question existing approaches to the computerization of the workplace, but most importantly, to create visions of different kinds of future workplaces and practices and to design the new computer based systems that would shape them ${ }^{4}$. The active involvement of those who would use these new technologies was key to these activities. The projects aimed at supporting users and enable them to utilize and enhance their skills rather than constraining, controlling, or automating their work tasks. This meant that new ways of designing needed to be developed that, in turn, relied on finding new ways of cooperating between end users and professional system developers. It is the motivation behind this essential, emancipatory commitment and the context from which it emerged that has been so important to the development of Participatory Design since.

The Participatory Design research community gathers at the international Participatory Design Conferences (PDCs). The conference started as a dialogue about user involvement in IT systems development between, on the one hand Scandinavian scholars and promoters and, on the other Europeans and Americans interested in how the Scandinavian experience could be adopted and extended. The first was held in Seattle in 1990 and PDCs have been held every second year since. They continue to provide an important venue for international discussion of the collaborative, social, ethical, and political dimensions of design. Today, Participatory Design is a wellestablished area of research and an important practice within many areas of design. The idea of user participation is no longer new. Participation within information and communication technology design is widely accepted through iterative design techniques such as mock-ups and prototyping. User participation is also practised, in 
different ways, by many designers of different interactive products and is central to the developing of understandings and practices that are defining current trends in design thinking. But the meaning of participation does not reduce to 'involvement' and Participatory Design is not the same as 'user-centred design'; though the two can have much in common, especially regarding some of the design tools and techniques that are used. While many areas of design now pay at least lip service to people's participation, the question of how participation is being negotiated and defined (and by whom) is fundamental.

Participatory Design projects are always driven by ongoing and systematic reflection on how to involve users as full partners in design and how this involvement can unfold throughout the design process. The basic motivation remains democratic and emancipatory: active participation needs to be define Participatory Design because if we are to design the futures we wish to live then we need those whose futures are affected to actively participate in the design process. This is why it is so important that Participatory Design keeps developing processes, tools and methods needed to enable active and engaged participation in design activities wherever and whenever they occur.

Participation in Participatory Design means to investigate, understand, reflect upon, establish, develop, and support mutual learning processes as they unfold between the participants in collective 'reflection-in-action' during the design process. Designers strive to learn the realities of the situation of those who will use their designs while other participants strive to learn appropriate technological and other means to achieve their desired aims. Mutual learning throughout the Participatory Design process leaves all participants with increased knowledge and understandings: about what is being designed for the potential users; about people and their practices for designers; and all participants learn more about design.

Participatory Design has been defined by a strong commitment to understanding practice. This is because so much of what we do is guided by the recognition that designing the technologies people use in their every day activities shapes, in crucial ways, how those activities might be done. Understandings of practice, gained through various forms of ethnographic enquiry, are exploited as alternatives to the formal diagrams and heavily abstracted work flow processes that define traditional approaches to technology design. This means that practice plays a central 
epistemological role in Participatory Design that complements its rejection of technology driven formalisms and rationalist models of both work and design, along with their focus on individual work tasks. The focus on practice recognises the role of everyday practical action in shaping the worlds we live in. Most importantly, practice is understood as a social activity; it is the community that defines a given domain of work and what it means to accomplish it successfully ${ }^{5}$.

One of the greatest challenges in Participatory Design projects is for the process to continue long enough into the development and implementation of new products and situations for this mutual learning to be completed and for the process and its outcomes to be both reflected upon and otherwise evaluated. This has become increasingly challenging as these days technologies are rarely developed from scratch and more likely to be configured within specific settings. With the increasing availability of off-the-shelf products and the rise of domestic, mobile and embedded technologies attention has extended to include the configuration of individual components into useful devices and services ${ }^{6}$.

Practice changes over time, often in response to opportunities provided by new technologies and developing protocols about their use. How particular technologies are used and the roles they play are shaped by the situations in which they are embedded. The recognition that design is completed in use was shared by many of those involved in Participatory Design. During the 1990's this resulted in a marked interest in the tailorability of systems ${ }^{7-8}$ so users could adapt them to suit their needs after implementation.

This means that Participatory Design research and practice includes studies of actual technology use and ongoing re-configurations of particular settings and practices. The ongoing design iterations so central to Participatory Design practice can include evaluations of implemented technologies after they have been used for a period of time and can also be included as part of ongoing commercial projects ${ }^{9-13}$. Understanding practice that involves the use of actual technologies offers valuable opportunities to Participatory Design. Human activities are situated, that is, how they actually happen depends in fundamental ways on the material and social circumstances at hand ${ }^{14}$. 
Those working in Participatory Design know that involving people, who understand the practices and environments where new products and services will be used, as active participants in the design project means that the process and its outcome is more likely to be accepted and sustained. These people are, after all, the ones who know most about what the new designs need to do as well as the key actors in implementing change and making the new practice work. We have also learned over the years that when designing complex products the success of the outcome is fundamentally linked to the different voices able to contribute to its design. The results of the process are more likely to be flexible, robust, accessible to more people, more easily appropriated into changing situations and more adaptable to these situations over time.

There is an ethical stand underlying Participatory Design that recognises an accountability of design to the worlds it creates and the lives of those who inhabit them ${ }^{15}$. Working in genuine partnership with those who will use the technologies we build is our way of taking a stand about who we can be as designers and design researchers. Our ongoing challenges are to create the situations in which these partnerships can flourish and to develop the design processes, tools and methods needed to enable full and active participation in the full range of design activities.

\section{This volume}

This special issue: Challenges and Opportunities in Contemporary Participatory Design, presents insights from the past two biennial Participatory Design Conferences. Eight papers were selected for their exploration of a wide range of current challenges and directions in the field and these have been reworked, rewritten, and edited for the broader audience of Design Issues.

The theme for the tenth Participatory Design Conference, PDC 2008, was Experiences and Challenges. It was chosen to honour two decades of biannual conferences. Contributors were asked to reflect on past experiences and review the important lessons we have learned so as to ready ourselves for the new challenges of the future. Five papers from this conference were chosen as a basis for this Special Issue. Together they explore important trends, phenomena, developments and views 
on both participation and design, which in so many different ways challenge our traditions, our experiences and/or the current 'wisdom' within the field.

After marking the tenth conference with this important reflection on the past in the light of current issues and challenges, the eleventh Participatory Design Conference, PDC2010 was explicitly a forward-looking conference. Held in Sydney, for the first time outside the northern hemisphere, the conference theme, Participation $\because:$ the challenge was chosen to encourage an exploration of what participation can and needs to mean in current and future design contexts and to broaden participation in the conferences to include people from other design domains and from industry, particularly small design companies, as well as academia. Three papers from this conference have been developed for this Special Issue

Three of the articles in this special issue take up a call from Dan Shapiro ${ }^{16}$ to find ways of bringing Participatory Design into large development projects. Johannessen and Ellingsen argue that iterative and agile Participatory Design methods can be applied to large scale systems development but this implies that complex organisational issues are also addressed as part of the Participatory Design process. Their article is grounded in a health-related project as is Simonsen and Hertzum's account of the extraordinarily thorough 'wizard-of-oz' prototyping of a new electronic patient record system. They argue for the extension of well-known iterative approaches in Participatory Design to include the implementation of mature prototypes that can be evaluated during real work over an appropriate amount of time. This means that anticipated changes to practice can be followed but that emergent and opportunity-based changes also are allowed to contribute to ongoing design. These are the changes that can genuinely improve the quality and acceptance of future systems and drive the design of better workplaces and health systems in the future. Dalsgaard's paper moves away from information and communication technology development to examine the extension of Participatory Design methods and techniques onto urban planning. His paper reports on a large scale public project, where participatory approaches were used to bring new ideas from the local community into the design and building of a new municipal library and the services it could offer.

Four of the articles in this volume reflect the widening focus of Participatory Design to include a variety of community settings. DiSalvo, Louw, Holstius, Nourbakhsh and 
Akin contribute a thoughtful account of engaging ordinary people in creative design and through this their participation in the design of their local communities. Their particular focus was using technology for environmental sensing that then enabled the local community to organise actions around the results. Hess and Pipek provide a critical investigation of the extent to which online communities can form a basis for the Participatory Design of a commercial product through their account of how a software company invited its existing online user community to participate in the further development of their own product. A study of the design and use of social technologies in community settings grounds Hagen and Robertson's paper. They examine how social technologies are characterised by being designed through use, leading in turn to new forms of participation. Social technologies are widely used in self-reporting during design projects but when used in the design of social technologies themselves they offer many opportunities for seeding content and encouraging participation within the community for whom the technologies are being developed.

Participatory Design projects in developing countries have been a constant issue for Participatory Design for the past 20 years. Winschiers-Theophilus, Bidwell, Blake and Kapuire's account of African philosophy in Sub-Saharan Africa reminds of us the need to understand and comply with different cultural traditions in particular cultures and local environments, particularly how participation is understood and practiced we cannot assume that all our participants live and act within liberal democracies.

Finally, the strong relations between Participatory Design and the recent attention to design thinking are drawn out by Björgvinsson, Ehn and Hillgren. They suggest that some of the practical, political, and theoretical challenges of Participatory Design might be relevant to contemporary design thinking. In particular they argue for a move beyond designing objects and specific design projects to 'infrastructuring' design so that conditions are established for continuing participation in the design of solutions for complex issues and the envisagement of positive and sustainable futures. We hope that the readers of Design Issues will enjoy this volume with its presentation of some of the challenges and opportunities within contemporary Participatory Design. 


\section{References}

1. J. Simonsen, and T. Robertson (Eds.), Handbook of Participatory Design

(Routledge, 2012).

2. J Simonsen, J.O Bærenholdt, M. Büscher, and J.D. Scheuer (Eds.), Design

Research: Synergies From Interdisciplinary Perspectives (London: Routledge, 2010).

3. N. Cross, Design Participation (Academy Editions, 1972).

4. Morten Kyng, "Designing for a Dollar a Day,” Office: Technology and People (1989): $157-70$

5. Lucy A. Suchman, and Randall H. Trigg, "Understanding Practice: Video as a Medium for Reflection and Design," in Design At Work: Cooperative Design of Computer Systems, ed. Joan Greenbaum, and Morten Kyng (UK: Lawrence Erlbaum Associates, Chichester, 1991).

6. Ellen Balka, et al., "Reconfiguring Critical Computing in an Era of Configurability" (Paper presented at the Proceedings of the 4th decennial conference on Critical computing, Aarhus, Denmark August 20 - 24, 2005, 2005).

7. R.H. Trigg, and S. Bødker, "From Implementation to Design: Tailoring and the Emergence of Systematization in Cscw" (Paper presented at the Proceedings of the Computer Supported Cooperative Work Conference, Chapel Hill, NC, USA, October 22-26, 1994, 1994).

8. T. Robertson, "Shoppers and Tailors: Participative Practices in Small Australian Design Companies," Computer Supported Cooperative Work: The Journal of Collaborative Computing 7, no. 2-3 (1998): 205-21.

9. Jakob E. Bardram, et al., “Awaremedia - a Shared Interactive Display Supporting Social, Temporal, and Spatial Awareness in Surgery" (Paper presented at the Proceedings of the 20th Anniversary Conference on Computer Supported Cooperative Work, Banff, Alberta, Canada, November 04 - 08, 2006, 2006). 10. Susanne Bødker, and Jacob Buur, “The Design Collaboratorium - A Place for Usability Design," ACM Transactions on Computer-Human Interaction 9, no. 2 (2002): 152-69. 
11. Monika Büscher, M. A. Eriksen, J. F. Kristensen, and P. H. Mogensen, "Ways of Grounding Imagination" (Paper presented at the Proceedings of the eighth Participatory Design Conference, July 27-31, 2004 Toronto, Canada, 2004).

12. Thomas Riisgaard Hansen, et al., "Moving Out of the Laboratory: Deploying Pervasive Technologies in a Hospital," IEEE Pervasive Computing 5, no. 3 (2006): 24-31.

13. Jesper Simonsen, and Morten Hertzum, "Participatory Design and the Challenges of Large-Scale Systems: Extending the Iterative Pd Approach" (Paper presented at the Proceedings of the 10th anniversary conference on Participatory Design, September 30 - October 4, 2008, Bloomington, Indiana, USA, 2008).

14. Lucy A. Suchman, Plans and Situated Actions: the Problem of Human-Machine Communication (Cambridge, New York: Cambridge University Press, 1987).

15. I. Wagner, and T. Robertson, "Ethics: Engagement, Representation and Politicsin-Action," in Handbook of Participatory Design, ed. J. Simonsen, and T. Robertson (Routledge, 2012).

16. Dan Shapiro, "Participatory Design: The Will to Succeed" (Paper presented at the Proceedings of the 4th Decennial Conference on Critical Computing, Aarhus, Denmark August 20 - 24, 2005, 2005). 